\title{
Estresse em graduando de enfermagem: técnicas de relaxamento para lidar com fatores estressores
}

Stress in undergraduate nursing students: relaxation techniques to cope with stressing factors

\section{Introdução}

A modernidade trouxe o avanço das ciências e da tecnologia, que a cada dia trazem novas ideias e conhecimentos, exigindo de cada um de nós novas aprendizagens e adaptações. Essa demanda (nem sempre correspondida) é geradora de estresse $^{1}$, que vem a ser o resultado de um conjunto de reações do organismo frente a uma situação que exija uma adaptação, que exija grande esforço emocional para ser superada, e tem por característica se desenvolver em etapas ou fases. O estresse enquanto processo foi pensado inicialmente contendo apenas três fases: alerta, resistência e exaustão. Esse modelo foi chamado de trifásico² . Posteriormente, após várias pesquisas, identificou-se uma quarta fase denominada de fase de quase exaustão, que fica entre as fases de resistência e de exaustão. Desse modo, propôs-se um modelo quadrifásico para o estresse, expandindo assim o modelo trifásico ${ }^{1}$. Quanto mais tempo durar a situação estressora ou quanto mais grave ela for, mais estressada a pessoa pode ficar. No contexto universitário, o ajustamento e o sucesso acadêmico vão depender do desenvolvimento psicossocial do estudante, de suas expectativas em relação ao curso que escolheu e do apoio proporcionado pela instituição ${ }^{3}$.

O graduando de enfermagem, durante a sua formação e em especial no último ano, quando ocorre efetivamente o estágio curricular (o internato), experimenta a condição de "ser enfermeiro". Essa experimentação traz consigo o enfrentamento de algumas crenças construídas ao longo desse período, tais como: a condição supra-humana dos trabalhadores de saúde; a necessidade de ser competitivo para obter sucesso; o uso das expressões "missão samaritana" e "abnegação ab-
Celia Caldeira Fonseca Kestenberg ', Alexandre Vicente da Silva ${ }^{2}$, Janaina Mengal Gomes Fabri ${ }^{3}$, Natalia André Barbosa Silva ${ }^{4}$, Barbara Marins Santos Rosa $^{5}$ e Leonardo Mengue Branco ${ }^{6}$

\section{Resumo}

Este estudo (descritivo e quantitativo) objetiva identificar o grau de estresse dos estudantes de enfermagem participantes do projeto de extensão "Vivendo Vivências" e compreender se as técnicas de relaxamento empregadas foram consideradas significativas na avaliação dos estudantes. Foram analisados 213 Inventários de Sintomas de Stress de Lipp e 142 questionários de avaliação do projeto, respondidos por graduandos das turmas de 2009 a 2012 . Resultados mostram que $68,5 \%$ dos estudantes apresentam estresse. Destes, 54\% estão na fase II (resistência) e $14 \%$ na fase III (exaustão). Os sintomas físicos mais evidentes foram: cansaço constante $78,8 \%$ e problemas com a memória $91,8 \%$. Os sintomas psicológicos foram: irritabilidade excessiva $63 \%$; vontade de fugir de tudo $63,4 \%$. Presença de vulnerabilidade mista. Os resultados evidenciam que $60,57 \%$ referem o relaxamento (respiração, imagens mentais, relaxamento de Jacobson e Schultz) como atividade muito importante. Concluímos que os objetivos do estudo foram alcançados; o estresse identificado na vida dos estudantes pode ser gerenciado a partir da aprendizagem de técnicas de relaxamento, que são ferramentas simples e podem ser acessadas em qualquer tempo e lugar. $O$ projeto agrega valor à formação dos estudantes, porque favorece a aprendizagem de conhecimentos para além do previsto no currículo de graduação.
\end{abstract}

Palavras-chave: Estresse; Relaxamento; Enfermagems

Área Temática: Saúde

Linha de Extensão: Educação; Saúde
1 Professora Adjunta. UERJ. E-mail: celiaprofuerj@gmail.com 2Professor Assistente. UERJ. E-mail: alexvicentesilva@uol.com.br ${ }_{3}^{3}$ Professora Substituta. UERJ. E-mail: janalpj@hotmail.com

${ }^{4}$ Bolsista de Iniciação Científica. UERJ. E-mail: natalia_u3@hotmail.com

${ }^{5}$ Voluntária do Projeto de Extensão. UERJ. E-mail: babiimāins@hotmail.com ${ }^{6}$ Voluntário do Projeto de Extensão Saúde. UERJ. E-mail: leo_mbranco@ hotmail.com 
soluta" para explicar as necessidades de um bom trabalhador da saúde; a obrigação de salvar vidas.

Compreende-se que essas são ideias distorcidas, possivelmente algumas advindas do senso comum, outras repassadas e aprendidas ao longo da graduação. Elas certamente funcionarão, direta ou indiretamente, como ingredientes para o estresse, porque fomentam a criação de fantasias, expectativas irreais, cognições distorcidas, perfeccionismo $^{1,6}$.

Além das crenças, que funcionam como fatores estressores internos, também existem situações no cotidiano do graduando que passam a funcionar como fatores estressores externos. Dentre eles, pode-se citar: a relação que o aluno passa a ter com pessoas que vivenciam o processo da morte e do morrer; o cotidiano de trabalho ligado à dor, sofrimento, impotência, angústia, medo, desesperança, perdas e desamparo. Há ainda o desgastante desafio de cuidar de pessoas que se mostram "poliqueixosas", que têm dificuldade para aceitar ajuda; outras que são agressivas, irritadas, hostis, autodestrutivas, deprimidas, dependentes e inseguras.

Os estudantes cuidam também de outros pacientes que trazem a esperança de uma melhora rápida, indolor, sem sequelas e, no entanto, têm dificuldade em um investimento pessoal, atribuindo magicamente ao futuro profissional o poder da cura, o que lhes coloca numa situação de difícil saída. Além dessas, cabe ressaltar outra situação própria do cotidiano do acadêmico de enfermagem, que consiste em aprender a administrar o constrangimento de ter que lidar com a intimidade física e emocional do paciente, seja na hora do banho no leito, quando toca um corpo nu, ou ao escutar um segredo que lhe é revelado.

Outro aspecto a ser destacado refere-se à convivência com limitações de recursos materiais para desenvolver o cuidado técnico-instrumental; somam-se a isso suas próprias limitações pessoais para desenvolver as ações de enfermagem. $\mathrm{O}$ aluno tem que se confrontar com alto grau de expectativas e cobranças lançadas sobre ele pelos pacientes, familiares, professores e até por ele próprio. Todos exigem cuidado digno e correto, o que pode se constituir em desafios com os quais o aluno terá que lidar. Outro elemento estressor externo refere-se à intensa carga horária do internato. Os alunos do último ano enfrentam jornadas de estágio de 8 horas diárias e mais um plantão de 12 horas no fim de semana. Muitas vezes, os campos de práticas são distantes de suas casas e o deslocamento torna-se longo e cansativo; adicionalmente, os estudantes convivem com os problemas dos meios de transportes, que tornaram a mobilidade das pessoas nos centros urbanos um caos todos os dias. Vários alunos, depois da faculdade, seguem ainda para outros locais de trabalho realizando plantões noturnos, tendo que se deslocar de um ponto ao outro da cidade com rapidez inviável. Diante de tantos fatores estressores internos, referentes a questões intrapessoais, e de estressores externos, referentes ao meio ambiente, é possível perceber o solo fértil para o desenvolvimento do estresse, em diferentes níveis, nos estudantes de enfermagem.

$\mathrm{Na}$ tentativa de ajudar esses estudantes a lidarem de forma mais adequada com os fatores estressores no cotidiano acadêmico, é desenvolvido um projeto de extensão intitulado "Vivendo Vivências: laboratório de relações interpessoais e habilidades sociais em saúde", na faculdade de enfermagem da UERJ. O objetivo central do projeto é cuidar dos estudantes e ensinar relações de cuidado. Este artigo teve como objetivos: identificar o grau de estresse dos estudantes e identificar se as técnicas de relaxamento empregadas foram consideradas significativas na avaliação dos estudantes.

\section{Metodologia}

O projeto "Vivendo Vivências" é desenvolvido junto aos graduandos dos dois últimos períodos, que estão em estágio na modalidade de internato e cuja carga horária é de 1080 horas semestrais, distribuídas em 44 semanais, incluindo plantões de fim de semana. As atividades do projeto são desenvolvidas por meio de trabalho de grupo, utilizando o método vivencial. Em média são 16 encontros semestrais, cuja periodicidade é semanal com duração de 3 horas cada um. Cada encontro segue quase sempre o mesmo formato: primeiramente é realizado o relaxamento, a partir da adaptação de dois métodos: o relaxamento progressivo de Jacobson ${ }^{4}$ que consiste no relaxamento progressivo através de exercícios de tensão e relaxamento de grupamentos musculares para conseguir o relaxamento completo do indivíduo; e o método de treinamento autógeno de Scuhltz $z^{5}$, que consiste na indução da pessoa a uma situação de tranquilidade psíquica por meio da respiração, 
da redução de estímulos externos e da concentração voluntária e consciente em direção a funções sensoriais.

A segunda etapa se constitui de uma vivência de acordo com o objetivo a ser alcançado. Vivência é uma atividade estruturada de modo semelhante ou análogo às situações cotidianas de interação social dos alunos que mobiliza sensações, sentimentos, pensamentos e ações, com o objetivo de ampliar a consciência e a compreensão sobre um dado fenômeno/evento/situação.

A terceira etapa refere-se ao compartilhamento e feedback entre os membros do grupo, quando os coordenadores acrescentam reflexões a partir dos dados que emergiram.

A quarta etapa consiste no fechamento do grupo e sistematização do conhecimento. Nesse momento é solicitado aos alunos que exercitem nos contextos interacionais o que foi aprendido. Em todos os encontros, é ressaltada a importância de se atentar para a consciência corporal e o relaxamento como forma de aliviar o estresse.

Trata-se de um estudo descritivo/quantitativo, realizado a partir da análise de dois instrumentos: Inventário de Sintomas de Stress de Lipp ${ }^{1}$ e Questionário de avaliação do projeto. Foram analisados 213 Inventários respondidos por graduandos do oitavo período das turmas de 2009, 2010, 2011 e 2012 participantes do projeto de extensão "Vivendo Vivências". Foi feita a análise de 142 questionários de avaliação respondidos pelos estudantes pertencentes às mesmas turmas (de 2009 a 2012) selecionados aleatoriamente. Para este estudo, foi analisada a pergunta: quais atividades desenvolvidas você considerou mais significativas? Por quê? Para a análise dos dados foi utilizada a estatística descritiva. Todos assinaram o termo de consentimento livre e esclarecido (protocolo de pesquisa $\mathrm{n}^{\circ}$ 018.3.2008).

O Inventário de Sintomas de Stress de Lipp (ISSL) ${ }^{1}$ objetiva identificar a sintomatologia que o indivíduo apresenta, avaliando se este possui sintomas de estresse, o tipo de sintoma existente (se somático ou psicológico) e a fase em que se encontra. O ISSL é dividido em três etapas referentes às quatro fases do estresse anteriormente citadas, abrangendo os sintomas característicos de cada fase. No total, o ISSL inclui 37 itens de natureza somática e 19 de natureza psicológica, sendo os sintomas muitas vezes repetidos, diferindo apenas sua intensidade e gravidade. As respostas são: F1 e P1 no quadro 1, F2 e P2 no quadro 2 e F3 e P3 no quadro 3. É necessário frisar bem o período de tempo a que cada quadro do teste se refere, sendo 24 horas para o quadro 1 , uma semana para o quadro 2 e um mês para o quadro 3. Para sua avaliação e correção, o ISSL é dividido em etapas: Etapa 1 - somar os sintomas marcados no Quadro 1 (F1 + P1), Quadro 2 (F2 + P2) e Quadro 3 (F3 + P3); Etapa 2 - Escrever os escores brutos de cada quadro separadamente; Etapa 3 - Verificar se o escore bruto de algum dos 3 quadros atingiu um limite. Se os valores forem maiores que 5 no Quadro 1, ou maiores que 3 no Quadro 2 ou maiores que 8 no Quadro 3, o diagnóstico do estresse é positivo para esses casos. Se todos os escores estiverem abaixo desses limites, o diagnóstico é negativo para presença de estresse.

Para diagnosticar a fase do estresse em que a pessoa se encontra, é necessário correlacionar os escores brutos com porcentagens preestabelecidas em tabelas de correção do ISSL. A maior porcentagem obtida indicará a fase do estresse em que a pessoa se localiza. $O$ Quadro 1 corresponde à Fase de Alerta, o Quadro 2 é dividido em duas partes, nas quais escores de 4 a 9 (e suas porcentagens) indicam a Fase de Resistência e escores de 10 a 15 (e suas porcentagens) indicam a Fase de Quase Exaustão e, por último, o Quadro 3 corresponde à Fase de Exaustão. No caso de empate das porcentagens, o diagnóstico realizado é o da fase mais avançada. Durante a avaliação para saber se o indivíduo possui mais sintomas psicológicos ou físicos, é preciso considerar apenas a fase do estresse em que ele se encontra. Soma-se o total bruto dos sintomas psicológicos (P) e o total dos sintomas físicos (F). Nas tabelas de correção do ISSL encontram-se porcentagens referentes aos escores brutos dos sintomas físicos e psicológicos. A maior porcentagem revela onde é a área de maior manifestação do estresse e quais sintomas estão mais evidentes, levando-se em consideração que as porcentagens podem ser iguais, ou seja, as manifestações físicas e psicológicas possuem intensidades semelhantes ${ }^{1}$.

\section{Resultados/discussão}

A análise do inventário de estresse mostrou que a maioria dos estudantes (146), correspon- 
dendo a $68,5 \%$, apresentava algum grau de estresse. Desses, 115 (54\%) estavam na fase II, resistência, e 30 (14\%) na fase III, exaustão. Somente um aluno $(0,5 \%)$ estava na fase I, alarme. Quanto aos sinais e sintomas do estresse, foram identificados:

Físicos: sensação de desgaste físico constante, 111 (76\%); cansaço constante, 115 $(78,8 \%)$; problemas com a memória 134 (91,8\%), tensão muscular, 119 (55,87\%).

Psicológicos: cansaço excessivo, 75 (51,4\%); irritabilidade excessiva, 92 (63\%); vontade de fugir de tudo, 97 (63,4\%); pensar constantemente num só assunto, 81 $(55,5 \%)$.

A avaliação dos sintomas que mais apareceram indica a área (física ou psicológica) mais vulnerável ao estresse. Observa-se que as duas áreas estão vulneráveis, o que é identificado como vulnerabilidade mista, e que os sintomas apresentam percentual elevado, sugerindo que os graduandos que estavam na fase de resistência possivelmente precisavam de grande esforço para gerenciar o estresse. Os estudos na área de estresse indicam que nessa fase o organismo se esforça para reestabelecer a resistência do corpo a um nível semelhante ou superior ao inicialmente existente antes da atuação do fator estressor. É de suma importância compreender que 115 (correspondendo a 54\%) dos alunos avaliados que estão iniciando o internato estão na fase de resistência.

A resistência ${ }^{6,7}$ ao estresse está condicionada à higidez prévia do organismo atingido, à estrutura de personalidade da pessoa, à natureza, frequência e intensidade do fator estressor. Durante a fase de resistência, o organismo se acha adaptado ao estresse. Entretanto, se um novo estresse se sobrepõe, pode-se desfazer o equilíbrio construído e desencadear a fase seguinte, que é a exaustão. Do ponto de vista físico alguns sinais podem ser percebidos como: dismenorreia, esterilidade, elevação ligeira na pressão arterial sistólica, tensão muscular e desgaste físico constante. Do ponto de vista psicológico, podem ser percebidos: a exacerbação dos mecanismos de defesa, inquietação, intolerância, baixa resistência à frustração, irritação, agitação psicomotora, impulsividade, agressividade, alterações do sono, fadiga fácil, pensamento acelerado, lapsos de memória, dificuldades de concentração e atenção dispersiva. Observa-se que os estudantes de enfermagem que participaram do estudo também, em sua maioria, apresentam sintomas psicológicos.

O estudo mostra que 14\% dos alunos estão na fase de exaustão o que sugere que pode haver algum tipo de adoecimento físico, manifesto ou não. Caso não haja resolução da situação estressora ou se nada for feito para aliviar a tensão, o organismo estará cada vez mais exaurido e sem energia. É justamente na resolução ineficaz da sobrecarga de estímulos estressores durante a formação universitária que está fundamentada a premissa de que estudantes de enfermagem estão propícios a apresentar características evidenciáveis de estresse ${ }^{3}$. Segundo os autores que pesquisam o estresse ${ }^{1,6-8}$, a fase de exaustão evidencia uma falência no esforço de adaptação, surgindo aí o esgotamento das defesas da personalidade e dos mecanismos reguladores da homeostase. No nível físico, podem surgir alterações glicêmicas e na tensão arterial, o sangue se espessa, podem formar-se úlceras gastrointestinais, involução do sistema linfático, o córtex da suprarrenal pode apresentar áreas de hemorragia, degeneração e necrose, diminuem as resistências do organismo. Enfim, rompe-se o equilíbrio psiconeuroendocrinoimunitário e há a eclosão de doenças, podendo ocorrer até a morte.

No nível psicológico pode surgir angústia, depressão, falência dos mecanismos de defesa, apatia, labilidade afetiva, lapsos de memória mais frequentes, lentificação do pensamento, diminuição da atenção. Podem surgir ainda: ideação suicida, fadiga crônica, perda de motivação, prostração, insônia, isolamento, diminuição do interesse sexual, o indivíduo pode tornar-se poliqueixoso e resistente a ajuda. Esse dado pode ajudar na compreensão do comportamento de alguns alunos da faculdade que, por vezes, passam por pessoas difíceis de lidar. Em meio a outros, se confundem com aqueles estudantes que têm comportamento social inadequado e então não serão cuidados e correm o risco de potencializar as somatizações e adoecer.

O resultado das avaliações dos estudantes demonstra que o relaxamento ensinado e praticado em todos os encontros foi a atividade mais citada por eles. Das 142 avaliações, 86 correspondendo a $60,57 \%$ apontam o relaxamento como de grande importância: 
"As atividades de relaxamento foram importantes para mantermos o equilíbrio visto que passamos todo período em alto estado de tensão diante das múltiplas atividades do internato (interno $8^{\circ} \mathrm{p}$ )".

Relaxamento significa a diminuição de tensão, afrouxamento, relaxamento dos músculos. A fala do entrevistado corrobora com estudos anteriores que afirmam ser o relaxamento uma estratégia segura para reduzir o estresse em alunos de enfermagem $^{9,10}$. $\mathrm{O}$ cotidiano da prática profissional demanda do estudante aprender a lidar com o sofrimento e regular suas emoções, cuidar do ser humano integralmente quando ainda não se reconhece como um ser integral porque a maioria deles está saindo da adolescência. Além de tudo, o estudante necessita lidar com suas crenças construídas sobre o que é cuidar e o que é ser enfermeiro. Dependendo do tipo de crença existente, serão produzidos pensamentos distorcidos gerando sentimentos conflituosos e angustiantes que levam a ações desadaptativas.

Estudos anteriores ${ }^{10}$ afirmam que estudantes de enfermagem experimentam elevados níveis de estresse devidos à complexidade do curso e ao lidar com os limites humanos. Evidencia-se assim o quão importante é cuidar do estudante, ajudando-o a gerenciar o estresse. Aprender técnicas de relaxamento ajuda a lidar com o estresse oriundo não só do meio acadêmico, mas também do contexto social:

[...] todas as atividades tiveram grande importância, porém os que mais me tocavam eram as atividades de relaxamento, pois durante todo o período me senti extremamente necessitado de aliviar as tensões provenientes do internato e demais áreas da minha vida [...] (interno $8^{\circ} \mathrm{p}$ ).

O relaxamento pode combater muitos sintomas físicos e psicológicos do estresse. Estudos ${ }^{11}$ têm demonstrado que num estado de relaxamento profundo, as frequências respiratória e cardíaca e a pressão arterial podem diminuir, o metabolismo torna-se mais lento, a tensão muscular diminui, as pupilas se contraem e os vasos sanguíneos periféricos se dilatam, ocasionando um aumento da temperatura e uma sensação de calor nas extremidades.
Em estado de relaxamento ${ }^{11}$, o nível de consciência da pessoa passa da atividade beta, aquela que ocorre quando se está mentalmente lúcido e pensando ativamente, para a atividade alfa, um estado de consciência alterada. Os benefícios associados ao nível de consciência alfa incluem aumento da criatividade, da memória e da capacidade de concentração e melhora no comportamento adaptativo. Os indivíduos nesse estado prestam menos atenção a estímulos do ambiente externo e apresentam uma postura calma e tranquila. Nenhuma evidência de inquietação é percebida. É comum os olhos estarem fechados; os maxilares, separados; as mãos, espalmadas; os dedos, curvados; a cabeça, ligeiramente inclinada para o lado.

Cabe ressaltar que o estado alterado de consciência produzido pelo relaxamento nesses estudantes facilita o recebimento das sugestões de paz, tranquilidade, calma e bem estar dadas pelo coordenador do grupo vivencial. Dependendo do tipo de exercício de relaxamento, outros benefícios podem ser alcançados além de aliviar a tensão, conforme percebidos neste grupo como relaxamento para aprender a focar a atenção numa dada situação ou objetivo a ser alcançado. Uma das grandes preocupações dos alunos do ultimo ano refere-se á monografia, situação para à qual este exercício é bastante adequado.

No Grupo "Vivendo Vivências" costuma-se propor exercícios de respiração profunda, uma técnica simples que compõe uma das habilidades do relaxamento. A tensão é liberada quando os pulmões podem respirar o máximo de oxigênio possível. Pesquisas anteriores ${ }^{8,11}$ mostram que os exercícios respiratórios são eficazes na redução da ansiedade, depressão, irritabilidade, tensão muscular e fadiga, o que é ratificado neste estudo:

[...] as atividades mais significativas foram as de relaxamento e massagem, pois quando deitamos entramos em contato com nossa respiração e fazemos viagens incríveis, é possível se desligar dos problemas do dia-a-dia, aliviar o estresse. Depois dessas atividades, saio relaxada com a sensação de corpo e mente mais leves [...] (interno, $8^{\circ} \mathrm{p}$ ).

Os alunos são orientados a praticarem a respiração profunda no grupo e a fazerem o exercício em qualquer lugar e ocasião em que houver uma 
situação que gere tensão. Além da respiração, é exercitado o relaxamento progressivo de Jacob$\operatorname{son}^{4}$ que consiste no pressuposto de que o corpo responde a pensamentos e eventos que provocam ansiedade por tensão muscular. Cada grupo muscular é retesado por cinco a sete segundos e depois relaxados por 20 a 30 segundos, durante este tempo a pessoa se concentra nas diferenças de sensação entre as duas condições. Esta técnica é muito adequada para aqueles estudantes que tem maior dificuldade de concentração e costumam ficar inquietos. Ao contrair e relaxar a musculatura durante alguns minutos sob a orientação do coordenador do grupo observa-se que, gradativamente, a quietude vai tomando conta do corpo e então, o aluno se permite relaxar.

Outro exercício realizado com os estudantes é o relaxamento autógeno de Schultz. Nessa versão de relaxamento, a pessoa aprende a relaxar os músculos concentrando-se na sensação de relaxamento dentro dos músculos. As instruções podem ser fornecidas por um coordenador ou podem ser autoadministradas ${ }^{8,11}$. Os comandos seguem a direção da cabeça até os pés. O relaxamento pode ser facilitado por uma música de fundo suave e lenta tocada durante o exercício. Pode-se utilizar ainda como recurso para o relaxamento o exercício com imagens mentais. Essa técnica usa a imaginação na tentativa de reduzir a resposta corporal ao estresse ${ }^{8,11,12}$. A visualização é a mente pensando por imagens. No projeto, costuma-se usar com frequência esse recurso, e os alunos se beneficiam, como pode ser observado no relato a seguir:

\footnotetext{
“o que eu mais gostei foram os momentos de relaxamento porque pude me transportar para outros lugares e me esquecer das preocupações da vida" (interno, $8^{\circ} \mathrm{p}$ ).
}

O uso terapêutico da visualização está presente há séculos em muitas culturas, como a egípcia, a tibetana, a indiana, a africana, entre os esquimós e os índios americanos ${ }^{12}$. Nos tempos bíblicos, a visualização era uma técnica essencial para o tratamento de males físicos. Mais recentemente, essa técnica ressurge recebendo diversos nomes: sonho acordado dirigido, imaginação ativa, imaginação dirigida, psicossíntese, etc. Todas essas técnicas utilizam as imagens mentais no tratamento de doenças físicas. As visualizações propiciam a criação de situações novas, recriar velhas situações, ir além do estabelecido. Ela favorece a uma viagem profunda e experiencial pela vida interior, contribuindo assim para o autoconhecimento. Os estudantes revelam que foi possível ampliar o autoconhecimento e se beneficiarem do aprendizado no dia a dia:

“(...) eu tinha a chance de fazer contato com meu eu interior e estar tentando compreender algumas situações que eu estava vivenciando. Algumas técnicas, eu até pratico em casa, às vezes" (interno, $8^{\circ} \mathrm{p}$ ).

É o pensamento usado para fazer contato com nossa realidade interior subjetiva, já que esta é estruturada em imagens. A característica mais marcante de um trabalho com imagens é que ele pode ser acompanhado de mudanças fisiológicas. Muitos estudos $^{12}$ já exploraram as conexões entre mente e corpo. A psiconeuroimunologia é um exemplo desse esforço. Há uma correlação entre emoções negativas e baixa imunidade. Do mesmo modo, os pensamentos positivos se ligam a emoções positivas como o bom humor, alegria e felicidade. Os pesquisadores têm demonstrado que emoções positivas estão ligadas a boas reações imunológicas ${ }^{12}$.

Dessa forma, a utilização da técnica de imagens mentais permite eliminar pensamentos distorcidos, negativos e substituí-los por pensamentos novos, criativos e fecundos. Ao transformar esses pensamentos/imagens que estão em si, aos poucos cada pessoa vai transformando também seu autoconceito, sua autoestima e elaborando sentimentos mais positivos; vai construindo novos mecanismos de enfrentamento para as situações que geram tensão e dessa forma vai aprendendo a gerenciar melhor o estresse. Assim, é possível pensar que os estudantes que fizeram parte deste estudo e aprenderam as técnicas de relaxamento, levaram esse conhecimento, que passou a fazer parte de suas vidas, o que concorreu para aumentar seus níveis de saúde e bem estar.

\section{Conclusão}

A partir dos dados obtidos, conclui-se que os objetivos do estudo foram alcançados: compreender o grau de estresse em que se encontravam os estudantes de enfermagem que iniciavam o internato e identificar os sintomas físicos e psicológicos 
causados pelo estresse. O segundo objetivo possibilitou compreender e ampliar o conhecimento sobre os benefícios do ensino e prática de técnicas de relaxamento para redução dos efeitos do estresse em graduandos de enfermagem.

Este estudo contribuiu para se somar a outros que mostram a necessidade imperiosa de se colocar na agenda das instituições formadoras a atenção ao cuidador. Fontes estressoras estão presentes no complexo cotidiano dos enfermeiros. Várias são as estratégias possíveis para gerenciar o estresse, como uma melhor alimentação, exercícios físicos, inclusive uma modificação no estilo de vida. Sabe-se também que este último item, na maioria das vezes, não é muito fácil de ser colocado em prática. Então, sabendo-se da gravidade e da extensão do estresse na vida dos estudantes de enfermagem, futuros enfermeiros, é seguramente adequado e necessário o aprendizado de ferramentas simples, de baixo custo, que podem ser acessadas a qualquer tempo e lugar.

Sugere-se a partir desta investigação que outros estudos possam avaliar o grau de estresse dos alunos de todos os períodos da faculdade para se ter uma apreciação de outras variáveis que o influenciem. Além disso, considera-se relevante avaliar os fatores de proteção, ou seja, como os estudantes vêm lidando com o estresse no cotidiano da vida pessoal e acadêmica.

Conclui-se ainda que o Projeto "Vivendo Vivências" agrega valor à formação dos estudantes porque favorece a aprendizagem de conhecimentos para além do que está previsto nos currículos de graduação em enfermagem. Como futuros enfermeiros, poderão ser multiplicadores dessas habilidades em diferentes contextos profissionais, concorrendo para a concretização da política de humanização no âmbito da saúde.

\section{Referências}

1. LIPP, Marilda E. N. Inventário de sintomas de stress para adultos de LIPP. $3^{\mathrm{a}}$ ed. São Paulo: Casa do Psicólogo, 2005.

2. SELYE, Hans. Stress in Health and Disease. Boston: Butterworth, 1976

3. BOLSONI, A. Potencialidades e dificuldades interpessoais de universitários: estudo de caracterização. Acta comportamentalia. v. 19, n. 2, p.205-224. 2010.

4. JACOBSON, Edmund. Relax: como vencer as tensões. Tradução de Heloysa de Lima Dantas. São Paulo: Cultrix, 1981.
5. SCHULTZ, J. H. Auto-reflexão concentrativa/ exposição clínico-prática. São Paulo: Mestre Jou, 1967.

6. LIPP, Marilda E. N. Stress está dentro de Você. São Paulo: Contexto, 2000.

7. SEBASTIANI, R. W. Aspectos Emocionais e Psicofisiológicos nas Situações de Emergência no Hospital Geral. In: CAMON, V. A. A. Urgências Psicológicas no Hospital. São Paulo: Pioneira Thonson Learning, p. 18-21. 2002.

8. GREENBERG, G. S. Administração do Estresse. São Paulo: Manole, 2002.

9. TOWNSEND, M. C. Enfermagem Psiquiátrica conceito de cuidados. $3^{\mathrm{a}}$ ed. Rio de Janeiro: Guanabara Koogan, 2002. p. 164-167

10. BENAVENTE, S. B. T, COSTA A. L. S. Resposta fisiológicas e emocionais ao estresse em estudantes de enfermagem: revisão integrativa da literatura científica. Acta Paul Enferm. v. 24, n. 4, p.571-576. 2011.

11. MONTEIRO, Claudete F. S. Estresse no Cotidiano dos alunos de enfermagem da UFPI. Escola Anna Nery R Enfermagem v. 11, n. 1, p. 66-72. 2007.

12. EPSTEIN, G. Imagens que Curam práticas de visualização para a saúde física e mental. São Paulo: Editora Ágora, 2009. p 13-19.

\section{Abstract}

This study - both quantitative and descriptive - aims at identifying the degree of stress of nursing students taking part in the Community Project "Vivendo Vivências" and understand if the relaxation techniques applied were considered significant according to the students' evaluation. We analyzed 213 Lipp's Stress Symptoms Inventories and 142 project evaluation questionnaires, filled in by students of 2009 to 2012 classes. Results indicate that $68.5 \%$ of students show stress: $54 \%$ are in stage II (resistance) and 14\% in stage III (exhaustion). The most evident physical symptoms: constant fatigue $78.8 \%$, problems with memory $91.8 \%$. Psychological symptoms: irritability, $63 \%$, desire of escaping from all, $63.4 \%$. Presence of mixed vulnerability. Results indicate that $60.57 \%$ mention relaxation (breathing, mental images, Jacobson and Schultz relaxation) as very important activity. Conclusion: study objectives achieved; the identified stress in students' lives can be managed with learning relaxation techniques, simple tools that can be accessed at any time and place. The project adds value to students' education because it supports the acquisition of knowledge beyond that provided in the undergraduate curriculum.

Keywords: Stress; Relaxation; Nursing 